\title{
Motor synergies research in physical therapy: advantages of the uncontrolled manifold approach
}

\author{
Pesquisa de sinergias motoras em fisioterapia: vantagens da abordagem da variedade não controlada \\ Estudio de sinergias motoras en fisioterapia: ventajas del enfoque múltiple no controlado \\ Daniela Virgínia Vaz'
}

\begin{abstract}
Movement is central to physical therapy identity and practice. Advances in the science of movement control, motor learning and development are thus inextricably tied to professional development and clinical activity. This paper aims to describe a prominent approach to motor control with potential to greatly advance the understanding of movement dysfunction: the uncontrolled manifold (UCM). An argument is formulated for incorporating this method of data analysis in rehabilitation research. It is a narrative review of the relevant literature. Research in physical therapy could greatly benefit from investigating synergies with the theory and methods of UCM. Research should seek connections between functioning in daily life tasks and the assembling of synergies to stabilize different performance variables, the UCM variability measures, the synergy strength indexes, and the anticipatory synergy adjustments. Changes in these synergy variables should also be quantified after rehabilitation interventions. UCM can offer one solid science-based approach to inform clinical decisions on whether synergies have to be broken, rebalanced, created, or reinforced in patients with movement dysfunction.
\end{abstract}

Keywords I Motor Skills; Physical Therapy Modalities; Review.

RESUMO I O movimento humano é fundamental para a identidade e prática profissional da Fisioterapia. Avanços nas ciências do controle, aprendizagem e desenvolvimento motor são portanto inseparáveis do desenvolvimento da profissão e da atividade clínica. Este trabalho descreve uma abordagem importante de controle motor com grande potencial de contribuição para a investigação de disfunções de movimento: a abordagem da variedade não controlada (UCM). Argumentos para a incorporação dos métodos de investigação da UCM na pesquisa em reabilitação é apresentado. Trata-se de uma revisão narrativa da literatura relacionada. A pesquisa na Fisioterapia pode se beneficiar bastante da investigação de sinergias com a teoria e os métodos de análise de dados da UCM. A pesquisa deve investigar conexões entre atividades de vida diária e a formação de sinergias motoras para estabilizar diferentes variáveis de desempenho, assim como a distribuição de variabilidade das sinergias, sua força e seus ajustes antecipatórios. Mudanças nesses quantificadores de sinergias também devem ser investigadas após intervenções de reabilitação. A UCM é uma abordagem científica sólida para informar decisões clínicas sobre a necessidade de desfazer, reequilibrar, criar ou reforçar sinergias motoras dos pacientes com disfunção de movimento.

Descritores | Destreza Motora; Modalidades de Fisioterapia; Revisão.

RESUMEN | El movimiento del ser humano es esencial a la identidad y práctica profesional en Fisioterapia. Los avances en las ciencias de control, del aprendizaje y del desarrollo motor son inseparables del desarrollo profesional y práctica clínica. En este estudio se intenta describir un importante abordaje de control motor que puede contribuir a los estudios sobre los trastornos del movimiento: el enfoque múltiple no controlado (UCM). Se presentan argumentos para incorporar a los métodos de estudios de la UCM en rehabilitación. Se trata de una revisión sistemática de literatura. Las investigaciones en Fisioterapia se pueden favorecer del estudio de sinergias 
con la teoría y los métodos de análisis de datos del UCM. Se estudian las conexiones entre las actividades de la vida diaria y la formación de sinergias motoras para estabilizar los distintos niveles de rendimiento, así como la distribución de la variabilidad de las sinergias, su fuerza y sus ajustes de anticipación. Tras las intervenciones en la rehabilitación también se deben estudiar cambios en los valores de las sinergias. El UCM es un sólido abordaje científico para informar sobre decisiones clínicas a cerca de la necesidad de deshacer, reequilibrarse, crear o fortalecer las sinergias motoras de los pacientes con trastornos de movimiento. Palabras clave I Destreza Motora; Modalidades de Fisioterapia; Revisión.

\section{INTRODUCTION}

In 2013 the American Physical Therapy Association issued a statement addressing the role of physical therapy: The physical therapy profession will transform society by optimizing movement to improve health and participation in life ${ }^{1}$.

The profession will be responsible for monitoring an individual's movement system across the life span in order to promote optimal development, diagnose dysfunction, and provide interventions targeted at preventing or ameliorating restrictions to activity and participation. The movement system will form the basis of practice, education, and research of the professional ${ }^{2}$.

These statements make it very clear that movement is central to physical therapy identity and practice as a profession. Advances in the science of movement control, learning and development are thus inextricably tied to professional development and clinical activity. The influence of these scientific theories in professional activity may be implicit or explicit. Undoubtedly, as many of the clients of physical therapy services need to relearn or adapt their movement patterns, the way a clinician approaches, assesses and treats a patient's movement dysfunction will be influenced by his or her underlying knowledge and beliefs about motor control. It is thus fundamental that research programs in Physical Therapy analyze and incorporate theoretical and methodological advances of movement science. This paper aims to describe a prominent approach to motor control with potential to greatly advance the understanding of movement dysfunction: the uncontrolled manifold. Arguments will be made for the incorporation of this method of data analysis in rehabilitation research.

\section{MOTOR SYNERGIES}

A central concept of motor control theories is that of a synergy, a term most therapists are familiar with. The Oxford dictionary defines synergy as "The interaction or cooperation of two or more organizations, substances, or other agents to produce a combined effect greater than the sum of their separate effects" 3 . This notion of synergy as cooperation is reflected in the language used by therapists to classify primary muscle functions. Muscles can be classified as agonists, antagonists or synergists. Synergists are muscles that act as supporters: they are indirectly involved and play a more assistive role in producing movement.

The idea of pathological synergies has also been very important in the clinical practice of neurological rehabilitation. The concept of muscle synergies was first used by the neurologist Babinski (1857-1932). He identified the relation between cerebellum pathology and impaired muscle coordination and used the term "cerebellar asynergies" to refer to his patient's uncoordinated movements ${ }^{4}$. Brunnstrom created a wellknown taxonomy of pathological synergies in individuals with hemiparesis and other clinicians have used similar notions ${ }^{5-7}$. This usage of the concept of synergy refers to lack of 'selective motor control': children and adults with neurological dysfunction can only use mass movement or stereotyped patterns of movement due to abnormal neurological functioning. Usually, this clinical notion about synergies is underlined by the belief that they reflect a relatively primitive solution to motor coordination, that gets disinhibited or re-expressed when phylogenetically 'newer' neural structures like the cortex are injured ${ }^{8,9}$ e.g. following a stroke or cerebral palsy. Some treatment approaches aim to extinguish pathological synergies and create variability and flexibility (fractionation) in these patterns ${ }^{10,11}$.

For patients with musculoskeletal impairments, movement dysfunction has been associated with 
disrupted recruitment of muscles within synergies. Certain muscles can have preferential recruitment and become dominant over others in a muscle synergy. This imbalance can reinforce demand over stronger muscles and minimize demand over weaker ones thus creating a vicious cycle. Based on possible imbalances, Sahrmann ${ }^{12}$ has developed a system for the diagnostic classification of muscle impairment syndromes. Treatment approaches aim to reestablish the appropriate balance in muscle activation patterns.

In motor control science, the study of normal movement synergies has received significant attention for over a century in response to the identification of a fundamental problem: the problem of degrees of freedom ${ }^{13,14}$. To produce coordinated movements, many thousands of motor units or dozens of muscles must be controlled by the CNS. If muscles are constrained to act and change together as a group, motor behavior is produced by the combination of groups of muscles, with a much smaller number of variables controlled by the $\mathrm{CNS}^{13}$. According to this view, synergies are neurallyestablished functional muscle groupings that simplify body control ${ }^{15}$. Empirically, the concept of synergies finds support on the experimental findings of correlated muscle activations during several functional tasks. The understanding of normal and abnormal synergies and their changes during recovery and learning will indicate, from a therapeutic standpoint, whether synergies have to be broken, rebalanced, created, or reinforced. The study of synergies is therefore fundamental to develop movement therapies ${ }^{16}$.

\section{SOME METHODS TO STUDY MOTOR SYNERGIES}

Synergies are central in the understanding of both unimpaired and disordered motor coordination. To study any phenomenon, one has to be able to define it and also have adequate methods to identify and quantify it $^{17}$. In rehabilitation, with the increasing importance of evidence-based practice, researchers and clinicians are interested on objective measurement instruments. If movement is so central to physical therapy and many treatment approaches aim to influence synergies, tools for measuring synergies are essential. A clearly established measure is a requisite for therapists to quantify progress and adjust the therapeutic process to produce the desired outcome. Although the following methods are not clinical measures but measures used in motor control research, they can provide the basis for comprehension of scientific literature on synergies and eventually, the development of future measurement instruments for clinical use.

Different methods are available to define whether elements of the movement system are working coherently together, i.e., forming a synergy. If elements of the movement system are organized in a synergy, these elements should display shared activity or covariation. Therefore, many quantification methods are based on the application of correlation analyses, matrix factorization and other linear decomposition techniques on multidimensional movement data. These techniques look for regularities or patterns in muscle activation (or kinetic and kinematic variables) during the execution of a movement task or across changes in task conditions. If important regularities are present, these methods allow describing the movement task with fewer variables than the original data set. The reduction of the original multidimensional data set to a lower-dimensional set of factors indicates that original movement variables vary together as a group in important ways. It provides support for the existence of neurally-established functional muscle groupings - the synergies ${ }^{4,18}$.

For example, Principal Component Analysis is based on the definition of components or vectors that capture the greatest amount of variance in a data-set, revealing its internal structure. The number of principal components is less than or equal to the number of original variables. If the analysis results in only a few principal components representing the majority of the covariation of muscle activations or joint motions present in the data, it provides a strong support for a control strategy that constrains elements of the movement system to work coherently together as a synergy ${ }^{4}$.

However, the most critical aspect of synergies is not captured by these methods ${ }^{4,19}$. The presence of synergies implies not only that numerous motor elements share an activity pattern, it also implies that motor elements have a particular organization that is specific to a task. Synergies serve functional goals. Synergies are formed to allow a stable and flexible performance in a specific functional task such as standing up, maintaining balance, reaching for an object, brushing teeth, walking, or jumping. A synergy can be described as "coordination with a purpose"19. But none of the linear decomposition techniques used to identify synergies from movement data-sets relates the shared activity of the many motor 
elements to functional performance. These methods assume that synergies exist abstractly, independently from functional purposes ${ }^{20}$. Given the importance of synergies to functioning, one investigation tool seems particularly suited to the interests of physical therapists: the uncontrolled manifold (UCM).

\section{SYNERGIES ACCORDING TO THE UCM PERSPECTIVE}

Viewing synergy as a functional rather than an abstract concept, the UCM method investigates synergies with reference to what they are supposed to do: allow stable and flexible performance in a specific movement tasks. According to the UCM approach, synergies have three fundamental characteristics ${ }^{4}$ :

1) task-dependence, that is, synergies are organized to fulfill a specific functional purpose.

2) sharing, that is, numerous motor elements (called elemental variables) share an activity pattern.

3) flexibility/stability, that is, flexible (variable) combinations of the elemental variables are used to ensure a stable (repeatable) task performance.

In this perspective, a synergy is defined as an organization of elemental variables - the motor elements - that stabilizes an important performance variable ${ }^{4,17}$. As will become clear below, elemental and performance variables are central to the definition. The UCM concept of synergies comes with a computational method of analysis that is very useful to investigate normal and atypical movements.

A synergy can be investigated computationally with reference to a manifold. A manifold is a set of points that is well organized in a mathematical space. The points that populate this space are the elemental variables: basic descriptive variables representing the motor elements that share or participate in a given movement task. They may form a synergy.

For example, for the task of pointing with the index finger in the horizontal plane while sitting, one could hypothesize that the CNS should organize the participating elemental variables (e.g. angles of the shoulder, elbow, forearm, wrist and metacarpophalangeal and interphalangeal joints) so as to produce the required index finger coordinates. Would the candidate elemental variables form a "finger pointing" synergy? A UCM analysis can be used to answer that question.

Note that because there is redundancy in the motor system, several combinations of joint angles can all lead to the same required finger coordinates, that is, they can produce a stable or repeatable pointing performance. These various combinations define a mathematical space that is called UCM. Because all the various combinations of joint angles within this manifold lead to a stable pointing performance, it is hypothesized that little control is exerted by the CNS over these joint angles. This space of movement solutions, this manifold, is called 'uncontrolled' because elemental variables are free to vary and solve the finger pointing task flexibly, as long as they stay within the UCM. Some combinations of joint angles, however, interfere with the finger coordinates and would destabilize the performance. These combinations are outside the UCM. It is hypothesized that the controller would try to bring the variable values back to the UCM if they deviate from it.

In summary, according to the UCM theory, a movement task having been determined, the CNS selects a variety of values to be shared between elemental variables so as to keep performance stable. Redundancy (or rather abundance) ${ }^{21,22}$ is used to produce functional movements that are flexible and adaptable to changing contexts. This means that synergies serve to produce not a single coordinated movement pattern for a functional task, but a family of them (the UCM).

According to the UCM theory, analysis is based on quantifying movement variability at the level of elemental and performance variables. While elemental variables correspond to the motor elements of a synergy, performance variables correspond to aspects of the task that are important for its functional success, and are thus prioritized in movement control. For example, upper arm joint angles can be the elemental variables that form a synergy to stabilize the coordinates of finger pointing, a performance variable. To investigate whether this is the case, the research's participants will perform several repetitions of the pointing task. Usually, a biomechanical model that relates the elemental variables to the performance variable is created. This model is used to define the UCM: a mathematical space containing all the combinations of values of the elemental variable that do not affect the value of the performance variable. Data from elemental variables pertaining to several repetitions of a task is used to 
compute projections of variance. Part of the variance of the elemental variables will be found inside the UCM and such variability will be consistent with a stable pointing performance. Another part of the variability will be outside the UCM and will be associated with deterioration of pointing performance. In general, a synergy stabilizing the performance variable is said to exist if most of the normalized variability falls within the UCM.

\section{INVESTIGATING SYNERGIES WITH UCM IN POPULATIONS WITH MOVEMENT DISFUNCTION}

Within the UCM perspective, a synergy never exists by itself. By definition, it always serves a purpose: producing covariation among elemental variables to provide stability to some performance variable. The method can be used to compare several candidate taskrelevant performance variables. For example, during sit to stand, do joint motions organize synergistically to stabilize the center of mass, the center of pressure, or the position of the head?23,24. In other words, the method allows the investigation of which performance variable is being prioritized by the control mechanisms. This aspect of the method is very relevant in the study of atypical populations.

Atypical movements have traditionally been interpreted as abnormal, although such interpretation has been disputed to some extent. Altered movement patterns can be suboptimal and can also be adaptive to primary deficit. Adaptive atypical patterns would reflect an effort of the neuromuscular system to produce an adequate performance in face of primary deficits ${ }^{25,26}$. For example, bradykinesia in patients with Parkinson's disease may not be abnormal itself, but adaptive to deficits in pre-programming postural responses ${ }^{25}$. Gait patterns in children with cerebral palsy may be optimal depending on the available resources ${ }^{27}$. It is possible then, that patients with movement dysfunction might be using synergies that serve to stabilize different performance variables than those used by typical individuals. There would be, in these cases, "different priorities" in the CNS ${ }^{25}$. The UCM method allows testing hypothesis of this kind.

Also, once a performance variable is defined and a synergy is found stabilizing it, the UCM method allows synergies to be quantified and compared. This is important because atypical movements might be present even if the same performance variables are being "prioritized", that is, even if there are synergies stabilizing the same performance variables seen for typical populations. The method then allows discovering how the covariation of elemental variables differs between typical and patient populations.

Quantification of synergies is based on the calculation of two indexes of variability, sometimes referred to as good variability and bad variability. Bad variability is that found outside the $\mathrm{UCM}, \mathrm{V}_{\mathrm{ORT}}$, which is detrimental to the stability of task performance. Several clinical conditions characterized by unstable movement patterns, such as ataxia and Down syndrome are probably associated with higher than normal proportions of bad variability ${ }^{21}$ Good variability corresponds to variability of elemental variables found within the UCM, or $\mathrm{V}_{\mathrm{UCM}}$, that does not affect the performance variable. It is characterized as good because higher values of this index indicate more flexibility: the availability of varied movement patterns to accomplish the same task ${ }^{4,21,22}$. Such flexibility is very useful to deal with changing circumstances, such as unexpected perturbations ${ }^{28}$, fatigue of one of the elements ${ }^{29}$, and also secondary tasks ${ }^{30}$. Low $\mathrm{V}_{\mathrm{UCM}}$ is a sign of stereotypy ${ }^{21}$. Quantification of $\mathrm{V}_{\mathrm{UCM}}$ could thus be very useful to measure the effects of rehabilitation interventions in clinical studies. The available findings indicate that rehabilitation interventions should encourage increase in good variability by using non-repetitive tasks (to avoid stereotypical movements) while increasing the level of challenge.

With these two indexes, the strength of synergies can be measured. The higher the proportion of good variability (a synergy index) to bad variability, the stronger the synergy. Note that "stronger", in the sense of the UCM, does not mean more stereotypical patterns. On the contrary, it indicates more flexible and adaptable ways to perform a task. Weaker synergies may reflect low performance stability. Changes in the two variability indexes and in the strength of synergies can also be useful for the early detection of movement dysfunction for subclinical presentations ${ }^{4,21}$.

Finally, UCM analysis and theory opens up another very interesting venue of investigation about anticipatory synergy adjustments ${ }^{21}$. In many functional situations, the ability to switch between different synergies is of utmost importance. This is the case, for example, when someone who is standing has to take a step. By design, a posture stabilizing synergy would 
resist posture changes such as that which are necessary to produce the step. Therefore, the posture stabilizing synergy needs to be attenuated or weakened (a drop in the synergy index) to make room for the assembling of the stepping synergy. The same applies to movement initiation in general: without anticipatory synergy adjustments, any intended actions would be opposed by the person's own preexistent synergy. There is evidence that the CNS can indeed start turning a synergy off before a planned quick action ${ }^{31}$. Difficulties to regulate anticipatory synergy adjustments might be the cause of slowness of movement in the elderly, the movement difficulties of patients with Multiple Sclerosis ${ }^{32}$ and the freezing episodes of patients with Parkinson's disease ${ }^{21}$. A recent study indicated that dopaminergic drugs can improve the strength of synergies and the anticipatory adjustments in these patients ${ }^{33}$. Additionally, deficits in anticipatory synergy adjustments might serve as preclinical markers of neurological dysfunction ${ }^{34}$.

\section{CONCLUDING REMARKS}

Research in physical therapy could greatly benefit from investigating synergies with the theory and methods of UCM. Researches should seek connections between activities of daily living such as walking, jumping, running, maintaining upright balance, reaching, standing up etc., and the assembling of synergies to stabilize different performance variables, the variability measures $\mathrm{V}_{\mathrm{UCM}}, \mathrm{V}_{\mathrm{ORT}}$, the synergy strength indexes, and the anticipatory synergy adjustments. Changes in these synergy variables should also be quantified after rehabilitation interventions. UCM can offer one solid movement science-based approach to inform clinical decisions on whether synergies have to be broken, rebalanced, created, or reinforced. Its use in physical therapy research can help advance the APTA vision that "The movement system will form the basis of practice, education, and research of the profession".

\section{REFERENCES}

1. American Physical Therapy Association. Vision statement for the physical therapy profession [Internet]. Alexandria: American Physical Therapy Association; 2013. [access on Mar. 07, 2017]. Available from: http://www.apta.org/Vision/

2. American Physical Therapy Association. Guiding principles to achieve the vision [Internet]. Alexandria: American
Physical Therapy Association; 2013. [access on Mar. 07, 2017]. Available from: http://www.apta.org/Vision/

3. English Oxford Living Dictionaries [Internet]. Oxford: Oxford University Press; c2017. Synergy. [access on Mar. 07,2017]. Available from: https://en.oxforddictionaries.com/definition/synergy

4. Latash ML. Synergy. Oxford: Oxford University Press; 2008.

5. Brunnström S. Movement therapy in hemiplegia: a neurophysiological approach. New York: Harper \& Row, 1970.

6. Bobath B. Adult hemiplegia: evaluation and treatment. 3a ed. Oxford: Butterworth-Heinemann; 1990.

7. Fugl-Meyer AR, Jääskö L, Leyman I, Olsson S, Steglind S. The post stroke hemiplegic patient: 1. a method for evaluation of physical performance. Scand J Rehabil Med. 1975;7(1):13-31.

8. Giszter S, Patil V, Hart C. Primitives, premotor drives, and pattern generation: a combined computational and neuroethological perspective. Prog Brain Res. 2007;165:32346. doi: 10.1016/S0079-6123(06)65020-6.

9. Tresch MC, Saltiel P, d'Avella A, Bizzi E. Coordination and localization in spinal motor systems. Brain Res Brain Res Rev. 2002;40(1-3):66-79.

10. Tresch MC, Jarc A. The case for and against muscle synergies. Curr Opin Neurobiol. 2009;19(6):601-7.

11. Dipietro L, Krebs HI, Fasoli SE, Volpe BT, Stein J, Bever C, Hogan N. Changing motor synergies in chronic stroke. J Neurophysiol. 2007;98(2):757-68.

12. Sahrmann S. Diagnosis and treatment of movement impairment syndromes. Maryland Heights: Mosby; 2002.

13. Bernstein NA. On dexterity and its development. In: Latash ML, Turvey MT. Dexterity and its development. New Jersey: Lawrence Erlbaum Associates; 1996. p. 3-246.

14. Turvey MT. Coordination. Am Psychol. 1990;45(8):938-53.

15. d'Avella A, Saltiel P, Bizzi E. Combinations of muscle synergies in the construction of a natural motor behavior. Nat Neurosci. 2003;6(3):300-8. doi: 10.1038/nn1010.

16. Damiano D. Muscle synergies: input or output variables for neural control? Dev Med Child Neurol. 2015;57(12):1091-2. doi: 10.1111/dmcn.12843.

17. Latash ML, Anson JG. Synergies in health and disease: relations to adaptive changes in motor coordination. Phys Ther. 2006;86(8):1151-60.

18. Latash ML, Zatsiorsky V. Biomechanics and motor control: defining central concepts. San Diego: Academic Press; 2015.

19. Latash ML, Scholz JP, Schöner G. Toward a new theory of motor synergies. Motor Control. 2007;11(3):276-308.

20. Torres-Oviedo G, Ting LH. Muscle synergies characterizing human postural responses. J Neurophysiol. 2007;98(4):2144-56.

21. Latash ML, Huang X. Neural control of movement stability: lessons from studies of neurological patients. Neuroscience. 2015;301:39-48. doi: 10.1016/j.neuroscience.2015.05.075.

22. Latash ML. The bliss (not the problem) of motor abundance (not redundancy). Exp Brain Res. 2012;217(1):1-5. doi: 10.1007/ s00221-012-3000-4.

23. Scholz JP, Schöner G. The uncontrolled manifold concept: identifying control variables for a functional task. Exp Brain Res. 1999;126(3):289-306. 
24. Greve C, Zijlstra W, Hortobágyi T, Bongers RM. Not all is lost: old adults retain flexibility in motor behaviour during sitto-stand. PloS One. 2013;8(10):e77760. doi: 10.1371/journal. pone.0077760.

25. Latash ML, Anson JG. What are "normal movements" in atypical populations? Behav Brain Sci. 1996;19(1):55-68. doi: 10.1017/S0140525X00041467.

26. Holt KG, Obusek JP, Fonseca ST. Constraints on disordered locomotion: a dynamical systems perspective on spastic cerebral palsy. Hum Mov Sci. 1996;15(2):177-202. doi: 10.1016/0167-9457(95)00043-7.

27. Fonseca ST, Holt KG, Fetters L, Saltzman E. Dynamic resources used in ambulation by children with spastic hemiplegic cerebral palsy: relationship to kinematics, energetics, and asymmetries. Phys Ther. 2004;84(4):344-54.

28. Mattos DJ, Latash ML, Park E, Kuhl J, Scholz JP. Unpredictable elbow joint perturbation during reaching results in multijoint motor equivalence. J Neurophysiol. 2011;106(3):1424-36. doi: 10.1152/jn.00163.2011.

29. Singh T, Varadhan SK, Zatsiorsky VM, Latash ML. Fatigue and motor redundancy: adaptive increase in finger force variance in multi-finger tasks. J Neurophysiol. 2010;103(6):29903000. doi: 10.1152/jn.00077.2010.

30. Zhang W, Scholz JP, Zatsiorsky VM, Latash ML. What do synergies do? Effects of secondary constraints on multidigit synergies in accurate force-production tasks. J Neurophysiol. 2008:99(2):500-13.

31. Zhou T, Wu YH, Bartsch A, Cuadra C, Zatsiorsky VM, Latash ML. Anticipatory synergy adjustments: preparing a quick action in an unknown direction. Exp Brain Res. 2013;226(4):565-73. doi: 10.1007/s00221-013-3469-5.

32. Jo HJ, Mattos D, Lucassen EB, Huang X, Latash ML. Changes in multidigit synergies and their feed-forward adjustments in multiple sclerosis. J Motor Behav. 2016; 1-11. doi: 10.1080/00222895.2016.1169986.

33. Falaki A, Huang $X$, Lewis MM, Latash ML. Dopaminergic modulation of multi-muscle synergies in postural tasks performed by patients with Parkinson's disease. J Electromyogr Kinesiol. 2017;33:20-6. doi: 10.1016/j.jelekin.2017.01.002.

34. Lewis MM, Lee EY, Jo HJ, Du G, Park J, Flynn MR, et al. Synergy as a new and sensitive marker of basal ganglia dysfunction: a study of asymptomatic welders. Neurotoxicology. 2016:56:76-85. 